\title{
Self-assessed health of young-to-middle-aged adults in an English-speaking Caribbean nation
}

\author{
This article was published in the following Dove Press journal: \\ Patient Related Outcome Measures \\ 30 September 2010 \\ Number of times this article has been viewed
}

\author{
Paul A Bourne \\ Neva South-Bourne \\ Department of Community Health \\ and Psychiatry, Faculty of Medical \\ Sciences, University of the \\ West Indies, Mona, Kingston, \\ Jamaica, West Indies
}

Background: Gender differences in self-assessed health in young-to-middle-aged adults are understudied in the English-speaking Caribbean nations.

Aims: The aims of the current research are to (1) provide demographic characteristics of young adults, (2) examine the self-assessed health of young adults, (3) identify social determinants that explain good health status for young adults, (4) determine the magnitude of each social determinant, and (5) reveal gender differences in self-assessed health.

Materials and methods: This study extracted a subsample of 3,024 respondents from a larger nationally cross-sectional survey of 6,782 Jamaicans. Statistical analyses were performed using the SPSS v 16.0. Descriptive statistics were used to provide demographic information on the sample. Chi-square was used to examine the association between nonmetric variables, and an independent sample $t$-test was used to test the relationships between metric and dichotomous categorical variables. Logistic regression examined the relationship between the dependent variable and some predisposed independent variables.

Results: One percent of the sample claimed injury and 8\% illness. Self-reported diagnosed illnesses were influenza (12.7\%), diarrhea (2.9\%), respiratory disease $(14.1 \%)$, diabetes mellitus (7.8\%), hypertension (7.8\%), arthritis (2.9\%), and unspecified conditions (41.2\%). The mean length of illness was 26 days ( $\mathrm{SD}=98.9)$. Nine social determinants and biological conditions explained $19.2 \%$ of the variability of self-assessed health. Biological conditions accounted for $78.1 \%$ of the explanatory model.

Conclusion: Injury accounts for a miniscule percentage of illness and so using it to formulate intervention policies would lack the necessary depth to effectively address the health of this cohort.

Keywords: health care-seeking, soft-assessed health, health status

\section{Introduction}

Gender differences in self-assessed health in young-to-middle-aged adults (ie, age range 15-44 years) are understudied in the English-speaking Caribbean. Previous studies that have examined young-to-middle-aged adults have focused on reproductive health, survivability, teenage pregnancy, substance use and abuse, HIV/AIDS, injuries, and the impact of injuries on health. ${ }^{1-7}$ Although studies on injuries have shown that young males, aged 15-44 years, are mostly affected by violent injuries, ${ }^{6,7}$ Jamaican statistics ${ }^{8}$ revealed that many of the deaths that have occurred in this age group can be accounted for by injuries. Injuries are among reasons for ill-health and by extension do not constitute a significant percentage of illness. Injuries account for most of the morbidities and/or mortalities in the world, ${ }^{7}$ but this is not typical of Jamaica, making
Correspondence: Paul A Bourne Department of Community Health Statistics, Faculty of Medical Sciences, University of the West Indies, Mona Campus, Kingston, Jamaica, West Indies Tel +l (876) 4576990

Email paulbournel@yahoo.com 
studies on injuries germane but lacking extensive coverage on health. Statistics on Jamaica show that of the 10 leading causes of mortality, in 2002, ${ }^{8-10}$ homicides and injuries were the 5 th and 10th causes of death, respectively. ${ }^{10}$ In 2004, statistics from the World Health Organization showed that injuries were the 4th leading cause of mortality in Jamaica, ${ }^{11}$ and in 2006, statistics from the Jamaica Ministry of Health ${ }^{9}$ indicated that injuries were not among the 5 leading cases of hospital utilization in Jamaica.

Therefore, policies in Jamaica have not been formulated using general health status research, but rather from data on injuries, reproductive health, survivability, and mortalities. Policy intervention on those issues is pertinent and cannot be neglected in the general pursuit of health. Using general health status and health conditions would provide invaluable insights from the individual's perspective on those issues that would in turn add value to addressing health concerns resulting from particular outcomes, such as pregnancies, mortality, injuries or crime, violence, and victimization by young adults. A study by Hambleton et al ${ }^{12}$ identified that illness constituted a significant percentage of the explanatory power of the selfassessed health of older Barbadians (aged $>60$ years), and although this provides some understanding of the effect of illness on the general health status and that which may be caused by injuries, the research identified other factors (ie, social determinants) that played roles in the determination of health status. In this study, social determinants denote the conditions in which people are born and nurtured, reside, work, and get older, inclusive of the health care system.

Injuries, therefore, do account for a percentage of ill-health, indicating that a study of their typologies is imperative but this cannot abate or replace a study on the general health of young adults. An extensive review of the health literature in the English-speaking Caribbean nations found a lack of studies on the general health status of young adults. Empirical literature showed that any study of health must combine biological and social determinants, ${ }^{13-25}$ elements that are also lacking for young adults. Recently, a study by Bourne $^{26}$ provided invaluable insights into the typology of health conditions and the demographic shifts in adolescents between 2002 and 2007. Tables 1-3 highlight hospital utilization for gunshot wounds, utilization for suicide attempts, and utilization for victim prolife of individuals in Jamaica for 2005. The data highlight the crime and hospital utilization profile, which indicates that health care utilization for these victims of crimes is mostly for persons between 14 and 45 years of age. Age 15-45 years does not only represent most of the victims of crime, mortality, and hospital utilization in Jamaica but also denotes the group being arrested for major crimes. Some of the issues are social and do affect mortality, but what about those persons in this group who are alive and fear being a victim of violence, as well as those who reside in those communities in which such incidences are perpetrated each day? In addition, what about their general health, as well as those members of this age group who are not likely victims owing to other social conditions, such as social hierarchy, area of residence, or those who do not reside in inner-city communities? It is within this context that this study chose to examine the self-reported health of this group in order to provide insights into the health of young-to-middle-aged adults and the social determinants that explain their health status.

Previous studies that have examined young-to-middleaged adults have substantially used the chronological age $<25$ years, but evidence exists in Jamaica that shows that the majority of the crimes are committed by those aged 15-44 years, yet no information is available on their health status. Research has investigated the criminology of

Table I Treatment for gunshot wounds at the accident and emergency departments of public hospitals by gender and age cohort (in \%): 1999-2002

\begin{tabular}{|c|c|c|c|c|c|c|c|c|}
\hline \multirow[t]{3}{*}{ Age cohort, years } & \multicolumn{8}{|l|}{ Year } \\
\hline & \multicolumn{2}{|l|}{1999} & \multicolumn{2}{|l|}{2000} & \multicolumn{2}{|l|}{2001} & \multicolumn{2}{|l|}{2002} \\
\hline & Male & $\overline{\text { Female }}$ & Male & $\overline{\text { Female }}$ & Male & $\overline{\text { Female }}$ & Male & Female \\
\hline$<5$ & 0.8 & 1.3 & 0.2 & 3.1 & 0.2 & 0.0 & 0.0 & 0.0 \\
\hline $5-9$ & 0.3 & 3.0 & 0.7 & 1.9 & 0.3 & I.I & 0.3 & 0.6 \\
\hline $10-19$ & 17.9 & 24.5 & 16.2 & 18.5 & 10.2 & 17.0 & 13.9 & 17.0 \\
\hline $20-29$ & 39.0 & 32.5 & 40.5 & 30.2 & 35.8 & 19.4 & 36.6 & 35.2 \\
\hline $30-44$ & 30.6 & 23.6 & 31.1 & II.I & 32.3 & 26.9 & 29.3 & 32.1 \\
\hline $45-64$ & 6.6 & 12.2 & 6.7 & 28.4 & 10.7 & 22.3 & 8.9 & 11.3 \\
\hline $65+$ & 3.5 & 3.0 & 2.3 & II.I & 6.7 & 12.7 & 8.8 & 3.6 \\
\hline Unknown & 1.4 & 0.0 & 2.2 & 1.2 & 3.8 & 0.7 & 2.3 & 0.6 \\
\hline Total, \% & 100 & 100 & 100 & 100 & 100 & 100 & 100 & 100 \\
\hline
\end{tabular}

Note: Calculated by Paul A Bourne from Annual Report, 2002 published by the Policy, Planning, and Development Division, Ministry of Health, Jamaica. 
Table 2 Visitation to the accident and emergency departments of public hospitals for attempted suicide by gender and age cohort (in \%): 2000-2002

\begin{tabular}{|c|c|c|c|c|c|c|}
\hline \multirow[t]{3}{*}{ Age cohort, years } & \multicolumn{6}{|l|}{ Year } \\
\hline & \multicolumn{2}{|l|}{2000} & \multicolumn{2}{|l|}{2001} & \multicolumn{2}{|l|}{2002} \\
\hline & Male & Female & Male & Female & Male & Female \\
\hline$<5$ & 0.0 & 0.0 & 1.0 & 0.0 & 1.0 & 0.9 \\
\hline $5-9$ & 0.0 & 3.4 & 2.0 & 0.0 & 2.0 & 3.5 \\
\hline $10-19$ & 19.0 & 39.3 & 13.0 & 49.4 & 13.0 & 38.3 \\
\hline $20-29$ & 24.1 & 36.0 & 20.0 & 34.8 & 20.0 & 36.5 \\
\hline $30-44$ & 34.5 & 13.5 & 13.0 & 6.7 & 13.0 & 17.4 \\
\hline $45-64$ & 12.1 & 2.2 & 4.0 & 3.4 & 4.0 & 0.9 \\
\hline $65+$ & 6.9 & 3.4 & 4.0 & 2.2 & 4.0 & 0.0 \\
\hline Unknown & 3.4 & 2.2 & 0.0 & 3.4 & 1.7 & 2.6 \\
\hline Total, \% & 100 & 100 & 100 & 100 & 100 & 100 \\
\hline
\end{tabular}

Note: Calculated by Paul A Bourne from Annual Report, 2002 published by the Policy, Planning, and Development Division, Ministry of Health, Jamaica.

this age cohort, but has not investigated their health status, factors that determine their health status, differences in health status based on the sexes, and the social challenges associated with planning for this age group. Although it is important to understand the crime profile of people in a society and implement plans to effectively deal with this reality, the health information available is inadequate; particularly in Jamaica, health information is available on reproductive health of women (15-49 years) and young men (15-25 years), but there is a paucity of literature on the general health status, factors that account for their health status, and health profiles of males and females aged 15-44 years. This is the rationale for the current research. The aims of this study are to (1) elucidate the demographic characteristics of young adults, (2) examine the self-assessed health of young adults, (3) compute the social determinants that explain good health status for young adults, (4) understand the magnitude of each social determinant, and (5) clarify the gender differences in self-assessed health; all this in order to assist public policy intervention, compare the differences between the current findings and those of the literature, and guide future research.

\section{Materials and methods}

This study extracted a subsample of 3,024 respondents (ie, age range 15-44 years) from a larger national crosssectional survey (The Jamaica Survey of Living Conditions [JSLC]) of 6,782 Jamaicans. The JSLC was commissioned by the Planning Institute of Jamaica (PIOJ) and the Statistical Institute of Jamaica (STATIN) in 1988. ${ }^{27}$ These 2 organizations are responsible for planning, data collection, and developing policy guidelines for Jamaica, and they have been

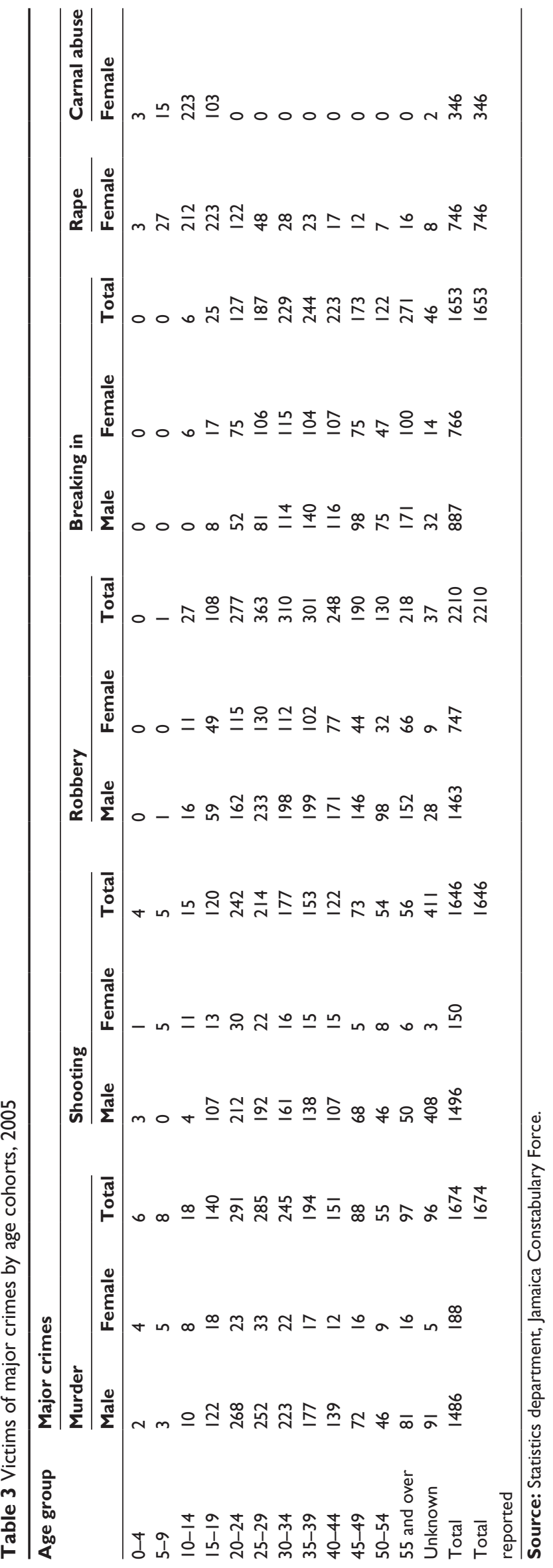


Table 4 Age group of persons arrested for major crimes for 2005

\begin{tabular}{|c|c|c|c|c|c|c|c|c|c|c|c|c|c|c|c|}
\hline \multirow{3}{*}{$\begin{array}{l}\text { Age } \\
\text { group }\end{array}$} & \multicolumn{15}{|c|}{ Major crimes } \\
\hline & \multicolumn{3}{|c|}{ Murder } & \multicolumn{3}{|c|}{ Shooting } & \multicolumn{3}{|c|}{ Robbery } & \multicolumn{3}{|c|}{ Breaking in } & \multirow{2}{*}{$\begin{array}{l}\text { Rape } \\
\text { Male }\end{array}$} & \multirow{2}{*}{$\begin{array}{l}\begin{array}{l}\text { Carnal } \\
\text { abuse }\end{array} \\
\text { Male }\end{array}$} & \multirow{2}{*}{ Total } \\
\hline & Male & Female & Total & Male & Female & Total & Male & Female & Total & Male & Female & Total & & & \\
\hline $12-15$ & 6 & 1 & 7 & 4 & 0 & 4 & 10 & 0 & 10 & 54 & 0 & 54 & 12 & 11 & 98 \\
\hline $16-20$ & 157 & 6 & 163 & 167 & I & 168 & 183 & 0 & 183 & 122 & 3 & 125 & 66 & 43 & 748 \\
\hline $21-25$ & 235 & 8 & 243 & 239 & I & 240 & 214 & I & 215 & 129 & 3 & 132 & 68 & 52 & 950 \\
\hline $26-30$ & 160 & 2 & 162 & 137 & 0 & 137 & 120 & I & 121 & 105 & 3 & 108 & 73 & 27 & 628 \\
\hline $31-35$ & 85 & 1 & 86 & 74 & 0 & 74 & 71 & I & 72 & 93 & 2 & 95 & 48 & 26 & 401 \\
\hline $36-40$ & 54 & 3 & 57 & 40 & 1 & 41 & 36 & I & 37 & 69 & 0 & 69 & 23 & 19 & 246 \\
\hline $4 I-45$ & 15 & 0 & 15 & 12 & 0 & 12 & 13 & 0 & 13 & 44 & 1 & 45 & 18 & 12 & 115 \\
\hline $46-50$ & 7 & 1 & 8 & 2 & 0 & 2 & I & 0 & 1 & 18 & 0 & 18 & 12 & 5 & 46 \\
\hline $51-55$ & 5 & 1 & 6 & 0 & 0 & 0 & 2 & 0 & 2 & 2 & 0 & 2 & 3 & 2 & 15 \\
\hline $56-60$ & I & 0 & I & I & 0 & I & 6 & 0 & 6 & I & 1 & 2 & I & I & 12 \\
\hline $\begin{array}{l}61 \text { and } \\
\text { over }\end{array}$ & 0 & 0 & 0 & 2 & 0 & 2 & 2 & 0 & 2 & 3 & I & 4 & 2 & 0 & 10 \\
\hline Unknown & 40 & 0 & 40 & 86 & 0 & 86 & 23 & 0 & 23 & 11 & 0 & 11 & 10 & 0 & 170 \\
\hline Total & 765 & 23 & 788 & 764 & 3 & 767 & 681 & 4 & 685 & 651 & 14 & 665 & 336 & 198 & 3439 \\
\hline
\end{tabular}

Source: Statistics Department, Jamaica Constabulary Force.

conducting the JSLC annually since $1989 .{ }^{28}$ The JSLC is an administered questionnaire in which respondents are asked to recall detailed information about particular activities. The questionnaire was modeled on the World Bank's Living Standards Measurement Study (LSMS) household survey. ${ }^{28}$ There are, however, some modifications to the LSMS, as the JSLC is more focused on policy impacts. The questionnaire covers demographic variables, health, immunization of children 0-59 months, education, daily expenses, nonfood consumption expenditure, housing conditions, inventory of durable goods, and social assistance. Interviewers are trained to collect the data from household members. The survey is conducted between April and July annually. This study used the data set of the JSLC for $2007 .{ }^{29}$

\section{Survey}

The survey was drawn using stratified random sampling. The design was a 2-stage stratified random sampling design where there was a primary sampling unit (PSU) and a selection of dwellings from the primary units. The PSU is an enumeration district (ED) that constitutes a minimum of 100 residences in rural areas and 150 in urban areas. An ED is an independent geographical unit that shares a common boundary. This means that the country is grouped into strata of equal size based on dwellings (EDs). Based on the PSUs, a listing of all the dwellings was made, and this became the sampling frame from which a master sample of dwellings was compiled, which in turn provided the sampling frame for the labor force. One-third of the labor force survey was selected for the JSLC. The sample was weighted to reflect the population of the nation.

\section{Measurement}

An explanation of some of the variables in the model is provided in this section. Self-reported illness is a dummy variable, where 1 (good health) $=$ not reporting an ailment or dysfunction or illness in the last 4 weeks, which was the survey period; 0 (poor health) if there were no self-reported ailments, injuries, or illnesses. Although self-reported illhealth is not an ideal indicator of actual health conditions because people may underreport, it is still an accurate proxy of ill-health and mortality. Self-reported illnesses are classified into acute and chronic conditions. These can be broadly defined as conditions that are prolonged, do not resolve spontaneously, and are infrequently curable. This is taken from the question "What are the illnesses that you have been diagnosed with - cold, diarrhea, asthma, diabetes mellitus, hypertension, arthritis, other chronic conditions (unspecified)?" The chronic conditions were diabetes mellitus, hypertension, and arthritis; and the acute conditions were cold (or influenza), diarrhea, and asthma. Self-reported injury was measured from the question "Have you had any injury during the last 4 weeks, due, for example, to an accident at your workplace, gunshot, stabbing, accidental fall, or other injury? Yes, due to motor vehicle accident; yes, accident at work place; yes, was shot; yes, was stabbed; yes, other accident; yes, burns; yes, head injury; yes, poisoning; and none. Social supports (or networks) denote different social networks with which 
Table 5 Demographic characteristics of the study population, $n=3,024$

\begin{tabular}{|c|c|c|c|}
\hline \multirow[t]{2}{*}{ Variable } & \multicolumn{2}{|l|}{ Gender } & \multirow[t]{2}{*}{$P$} \\
\hline & Male, $\% n=1,439$ & Female, $\%$ n = I,585 & \\
\hline Injury & & & 0.037 \\
\hline Yes & 1.4 & 0.6 & \\
\hline No & 98.6 & 99.6 & \\
\hline \multicolumn{4}{|l|}{ Illness } \\
\hline Yes & 5.3 & 10.5 & $<0.000$ I \\
\hline No & 94.7 & 89.5 & \\
\hline Self-assessed health status & & & $<0.0001$ \\
\hline Very good & 44.8 & 39.8 & \\
\hline Good & 47.5 & 47.4 & \\
\hline Moderate & 6.3 & 10.4 & \\
\hline Poor & I.I & 2.2 & \\
\hline Very poor & 0.4 & 0.2 & \\
\hline Health care-seeking behavior & & & $<0.000$ I \\
\hline Yes & 3.5 & 6.8 & \\
\hline No & 96.5 & 93.2 & \\
\hline Household head & & & $<0.000$ I \\
\hline Yes & 34.1 & 73.0 & \\
\hline No & 65.9 & 27.0 & \\
\hline Union status & & & 0.103 \\
\hline Married & 12.1 & 15.1 & \\
\hline Common-law & 19.7 & 21.0 & \\
\hline Visiting & 28.1 & 26.2 & \\
\hline Single & 30.8 & 28.9 & \\
\hline Not stated & 9.3 & 8.7 & \\
\hline Self-reported diagnosed health condition & & & 0.289 \\
\hline \multicolumn{4}{|l|}{ Acute } \\
\hline Influenza (or cold) & 12.9 & 12.7 & \\
\hline Diarrhea & 6.5 & 1.4 & \\
\hline Respiratory & 16.1 & 13.4 & \\
\hline \multicolumn{4}{|l|}{ Chronic } \\
\hline Diabetes & 6.5 & 8.5 & \\
\hline Hypertension & 11.3 & 21.1 & \\
\hline Arthritis & 1.6 & 3.5 & \\
\hline Other (unspecified) & 45.2 & 39.4 & \\
\hline Area of residence & & & 0.756 \\
\hline Urban & 32.2 & 31.9 & \\
\hline Periurban & 21.4 & 22.5 & \\
\hline Rural & 46.4 & 45.6 & \\
\hline No of visits to health care facilities, mean (SD) & $1.2(0.5)$ & $1.5(1.3)$ & 0.144 \\
\hline Age mean (SD) & $28.4 \mathrm{yr}(8.8)$ & $28.5 \mathrm{yr}(8.9)$ & 0.746 \\
\hline Medical expenditure mean (SD) in US\$a & $16.67(42.01)$ & $16.42(26.82)$ & $0.97 \mid$ \\
\hline
\end{tabular}

${ }^{\mathrm{a} U S} \$ 1.00=\mathrm{Ja} \$ 80.47$.

the individual is involved $(1=$ membership of and/or visits to civic organizations or having friends who visit one's home or with whom one is able to network, $0=$ otherwise). Psychological conditions are the psychological state of an individual, and this is subdivided into positive and negative affective psychological conditions. Positive affective psychological condition is the number of responses with regard to being hopeful and optimistic about the future and life generally. Negative affective psychological condition is the number of responses from a person on having lost a breadwinner and/or family member, having lost property, having been made redundant or failing to meet household and other obligations. Health status is a binary measure ( $1=$ good to excellent health; $0=$ otherwise) that is determined from "Generally, how do you feel about your health?" Answers for this question are on a Likert scale matter ranging from excellent to poor (ie, excellent, good, moderate, poor, and very poor). Health care-seeking behavior is derived from the question: Have you visited a health care practitioner, pharmacist, or healer in the last 4 weeks, with an option of yes or no. For the purpose 
of the regression, the responses were coded as $1=$ yes and $0=$ otherwise. Crowding is the total number of individuals in the household divided by the number of rooms (excluding kitchen, verandah, and bathroom). Age is a continuous variable, measured in years.

\section{Statistical analysis}

Statistical analyses were performed using the SPSS v 16.0 (SPSS Inc, Chicago, IL, USA) for Windows. Descriptive statistics such as mean, standard deviation (SD), frequency, and percentage were used to analyze the sociodemographic characteristics of the sample. Chi-square was used to examine the association between nonmetric variables, and an independent sample $t$-test was used to test the relationships between metric and dichotomous categorical variables. Logistic regression examined the relationship between the dependent variable and some predisposed independent (explanatory) variables because the dependent variable was a binary one (self-reported health status: $1=$ if reported good health status and $0=$ if reported poor health status). The final model was based on those variables that were statistically significant $(P<0.05)$, and all other variables were removed from it $(P>0.05)$. Categorical variables were coded using the "dummy coding" scheme or a reference category.

The predictive power of the model was tested using the "omnibus test of model", and Hosmer and Lemeshow's ${ }^{30}$ technique was used to examine the model's goodness of fit. The correlation matrix was examined in order to ascertain whether autocorrelation (or multicollinearity) existed between variables. Cohen and Holliday ${ }^{31}$ stated that correlation can be low/weak (0-0.39), moderate (0.4-0.69), or strong (0.7-1). This study used the above correlation to exclude (or allow) a variable. Finally, a forward stepwise technique in logistic regression was used to determine the magnitude (or contribution) of each statistically significant variable in comparison with the others and to determine the odds ratio (OR) for interpreting each of the significant variables.

\section{Analytic model}

The theoretical framework that underpins this study was a modification of Grossman's work, ${ }^{19}$ which models factors accounting for health status. Using econometric analysis, Grossman identified particular social determinants that account for self-reported health status. This approach allowed for ascertaining multiple factors, which point to the social determinants of health, and it is well established in the literature that this is acceptable in identifying those factors. ${ }^{12-26}$ Using the principles upon which Grossman developed the initial social determinants of health, Hambleton et $\mathrm{al}^{12}$ (using logistic regression) identified biological conditions which accounted for more of self-rated health than the social determinants of health.

Using logistic regression, this study sought to identify factors that account for the self-rated health of young adults; and these factors included social determinants of health and self-reported biological conditions, as was the case in Hambleton et al's work and a modification of Grossman's research.

To study the relationship between self-assessed health status and social determinants, biological conditions, welfare, and logistic regression were used to estimate the following regression model. Equation (1) denotes the 20 social variables $\left(\mathbf{S D H}_{i j}\right), 3$ welfare variables $\left(\mathbf{W}_{i j}\right)$, biological condition $\left(\boldsymbol{B}_{i}\right)$, self-assessed health status $\left(\boldsymbol{H}_{i}\right)$, and some standard errors:

$$
\boldsymbol{H}_{i}=f\left(\Sigma_{j=1}^{20} \boldsymbol{\beta}_{j} \mathbf{S D H}_{i j}, \Sigma_{j=1}^{3} \mathbf{W}_{j} \boldsymbol{B}_{i} \boldsymbol{\mu}_{i}\right)
$$

Table 6 presents the results from the econometric exercise, which is captured in Equation (2). Equation (2), therefore, presents only those variables that are significantly correlated with the self-assessed health status of young adults:

$$
\boldsymbol{H}_{i}=f\left(\Sigma_{j=1}^{9} \boldsymbol{\beta}_{j} \mathbf{S D H}_{i j}, \boldsymbol{B}_{i} \boldsymbol{\mu}_{i}\right)
$$

where

$H_{i}$ is the level of the self-assessed health status of person $i$ and $\mathrm{SDH}_{i j}$ denotes the 9 statistically significant social determinants of person $i$.

\section{Results}

The sample comprised 3,024 respondents: $47.6 \%$ males and $52.4 \%$ females. The mean age of the sample was 28.5 years $(\mathrm{SD}=8.8$ years). Thirty percent of the sample were single, $20.4 \%$ common-law, $13 \%$ married, and $27.1 \%$ in visiting unions. Of the sample, $36.3 \%$ were poor, with $17.1 \%$ in the poorest $20 \%$ compared with $44.1 \%$ in the wealthy social hierarchies, of which $23.2 \%$ were in the wealthiest $20 \%$. Of the sample, $45.9 \%$ dwelled in rural areas, $22 \%$ in periurban and $32.1 \%$ in urban areas. Of the sample population, with respect to the questions on injury and illness, $97.1 \%$ and $97 \%$ responded, respectively. Of those respondents, $1 \%$ claimed injury and $8 \%$ mentioned illness. When respondents were asked whether the illness was diagnosed and the typologies of conditions, $100 \%$ stated that the health condition was 
Table 6 Logistic regression: explanatory variables of good health status, $n=2,832$

\begin{tabular}{|c|c|c|c|c|c|}
\hline Explanatory variable & Standard error & Odds ratio & $95 \% \mathrm{Cl}$ & $P$ & $R^{2}$ \\
\hline \multicolumn{6}{|l|}{ Social determinants } \\
\hline Age & 0.01 & 0.97 & $0.96-0.99$ & $<0.0001$ & 0.004 \\
\hline Crowding & 0.03 & 0.95 & $0.90-1.00$ & 0.043 & 0.003 \\
\hline Tertiary & 0.28 & 1.47 & $1.27-1.81$ & 0.007 & 0.003 \\
\hline Primary ${ }^{\mathrm{a}}$ & & 1.00 & & & \\
\hline Male & 0.14 & 1.45 & $1.11-1.91$ & 0.007 & 0.006 \\
\hline Middle class & 0.18 & 1.45 & $1.02-2.07$ & $0.04 I$ & 0.003 \\
\hline Poor classes ${ }^{\mathrm{a}}$ & & 1.00 & & & \\
\hline Married & 0.21 & 1.63 & $1.09-2.43$ & 0.018 & 0.004 \\
\hline Single $\mathrm{e}^{\mathrm{a}}$ & & 1.00 & & & \\
\hline Other town & 0.18 & 1.61 & $1.12-2.30$ & 0.009 & 0.005 \\
\hline Rural $^{\mathrm{a}}$ & & 1.00 & & & \\
\hline Medical expenditure & 0.00 & 0.99 & $0.99-1.00$ & 0.017 & 0.006 \\
\hline Health care-seeking & 0.29 & 0.35 & $0.20-0.62$ & $<0.000$ I & 0.009 \\
\hline \multicolumn{6}{|l|}{ Biological condition } \\
\hline Self-reported illness & 0.24 & 0.17 & $0.11-0.28$ & $<0.0001$ & 0.153 \\
\hline
\end{tabular}

Notes: Hosmer and Lemeshow goodness of fit $\chi^{2}=4.4(8), P=0.82$.

$-2 \mathrm{LL}=1615.7$

Nagelkerke $R^{2}=0.196$.

Abbreviation: $\mathrm{Cl}$, confidence interval.

aReference group.

diagnosed by a medical practitioner. The self-reported diagnosed health conditions were influenza (12.7\%), diarrhea $(2.9 \%)$, respiratory disease $(14.1 \%)$, diabetes mellitus $(7.8 \%)$, hypertension (7.8\%), arthritis (2.9\%), and other unspecified conditions (41.2\%). The mean length of illness was 26 days $(\mathrm{SD}=98.9)$, with 1 visit made to a health care practitioner in the previous 4 weeks. When respondents were asked if they had visited a health care practitioner (including healer, pharmacist, nurse, and midwife) in the previous 4 weeks, $64.2 \%$ said yes. The health care institutions were public hospitals (34.8\%), private hospitals $(7.0 \%)$, public health care centers $(14 \%)$, and private health care centers (51.6\%). Twenty percent of the sample had health insurance coverage, $89.6 \%$ claimed at least good health (including $42.2 \%$ very good self-assessed health) compared with $1.9 \%$ who stated at least poor health (including $0.3 \%$ very poor health). Only $1 \%$ of the studied population indicated having had an injury during the previous 4 weeks. Injuries were owing to motor vehicle accidents (33.3\%), domestic accidents $(25.9 \%)$, industrial accidents (14.8\%), domestic incidents (11.1\%), violence (11.1\%), and other conditions $(3.7 \%)$.

A cross-tabulation of health care-seeking behavior and illness shows no significant statistical association. Of those who sought medical care, $97 \%$ were ill compared with $94 \%$ of those who sought medical care in the previous 4 weeks.

A cross-tabulation between illness and age group revealed a significant statistical association $\left(\chi^{2}=39.4, P<0.0001\right)$. However, no significant statistical association existed between typology of self-reported illness and age group of study population $\left(\chi^{2}=38.7, P=0.132\right)$. Figure 1 provides the information on the age group and percentage of youngto-middle-aged adults who indicated having had an illness in the previous 4 weeks or a particular typology of illness.

No significant statistical association was found between health care-seeking and age group $(P=0.608)$ : age 15-19 years, $60 \%$; age $20-24$ years, $53.1 \%$; age $25-29$, $60.0 \%$; age $30-34$ years, $67.7 \%$; age $35-39$ years, $68.0 \%$; and age $40-44$ years, $69 . \%$.

No significant statistical relationship was found between health care-seeking behavior and social hierarchy ( $P=0.339$ ): poorest $20 \%, 51.1 \%$; poor, $69.2 \%$; middle class, $67.4 \%$; wealthy, $65.5 \%$; and wealthiest $20 \%, 67.7 \%$.

There is a statistical difference between age of respondents who reported having particular health conditions $(F$-test $=4.5, P<0.001)$. The mean ages of particular health conditions were influenza, 29.3 years ( $\mathrm{SD}=9.2)$; diarrhea, 32.2 years $(\mathrm{SD}=8.7)$; respiratory, 30.3 years $(\mathrm{SD}=9.6)$; diabetes mellitus, 37.3 years $(\mathrm{SD}=5.9)$; hypertension, 36.8 years $(\mathrm{SD}=7.1)$; and other, 29.9 years $(\mathrm{SD}=9.3)$.

Figure 2 shows young adults who reported injury (\%) and illness (\%) who dwelled in particular areas of residence controlled for sex of respondents. Figure 2 showed that over $50 \%$ of those with illness and injury dwelled in rural areas. However, there was no significant statistical relationship when illness and injury by area of residence was controlled by sex of respondents (illness - male $\chi^{2}=2.6, P<0.271$ and 


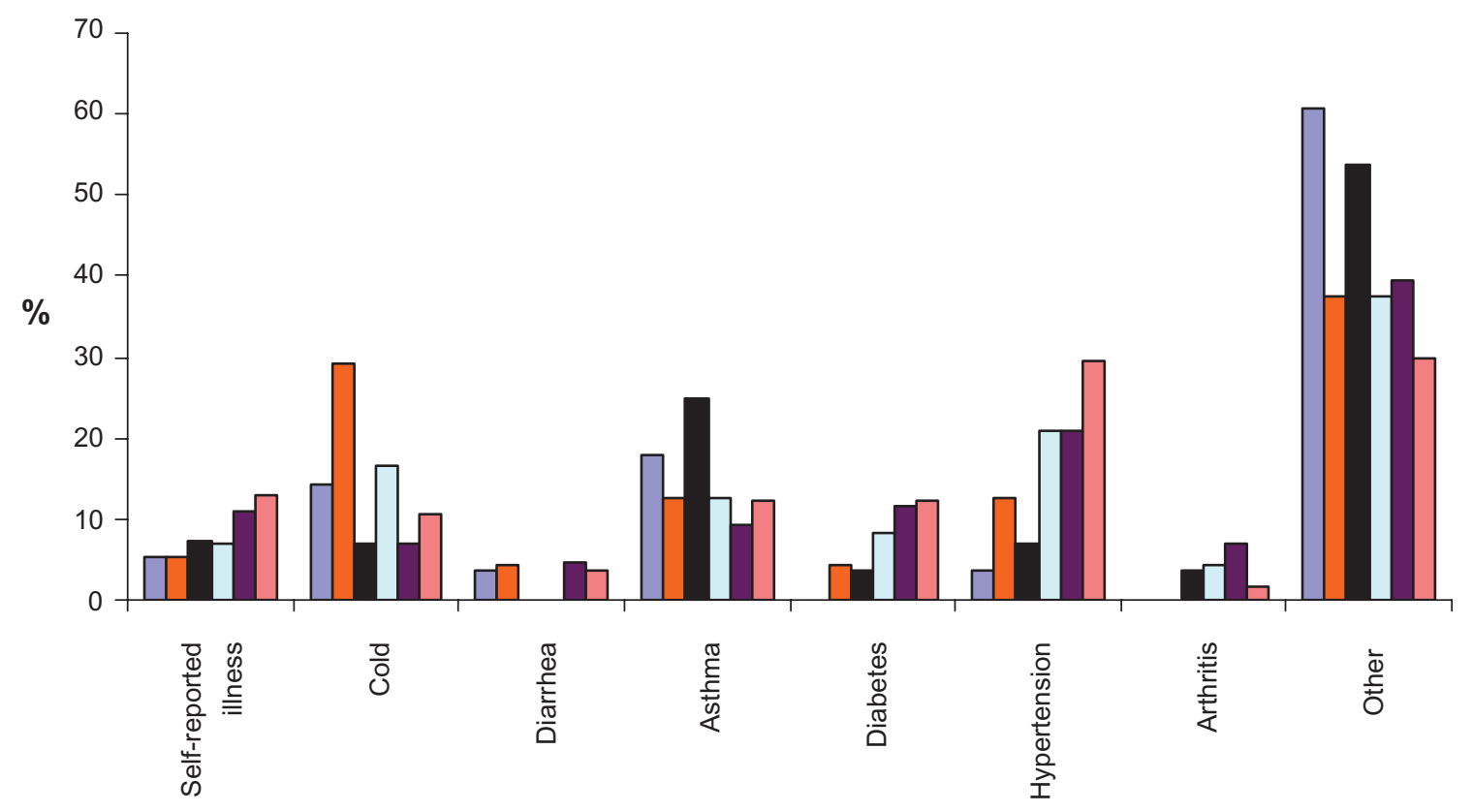

$\square$ 15-19 $\square$ 20-24 $\square$ 25-29 $\square$ 30-34 $\square$ 35-39 $\square$ 40-44

Figure I Self-reported illness (\%) and typology of self-reported illness by age group.

female $\chi^{2}=2.3, P<0.323$; injury - male $\chi^{2}=2.5, P<0.292$ and female $\chi^{2}=0.93, P<0.628$ ).

Figure 3 shows the gender composition of those who used health care facilities in Jamaica. Most young adult males used private hospitals (36.4\%) compared with females who visited public health care practitioners $(72.7 \%)$. The smallest percentage of females visited private hospitals $(63.6 \%)$ compared with public health care centers for males $(27.3 \%)$.

\section{Multivariate analysis}

Table 6 presents the results from the econometric exercise. Of the 24 variables tested in an initial model, 9 were social determinants and 1 was a biological variable. Biological variables (ie, self-reported illness) accounted for $78.1 \%$ of the explanatory power of the model (ie, 15.3\%), indicating that the social determinants accounted for $21.9 \%$ of the selfassessed health status of young adults.

\section{Limitations of study}

Health is a function of social, psychological, economic, biological, and ecological factors. Based on the multidimensional nature of health determinants, this study used secondary survey data and variables such as psychological and ecological factors; some social issues such as childhood health history, culture, belief, and value system were omitted from the model. These omissions reduced the explanatory power of this study, but it still provided a platform from which future studies can be launched. Using self-reported illness, and defining illness as a single biological variable in the multivariate analysis, is a limitation of this study, as illness is self-reported and, therefore, also a sociocultural concept, which can be accommodated among other social determinants of health.

\section{Discussion}

In this study, the prevalence of injury in Jamaica for youngto-middle-aged adults was $1 \%$ compared with $8 \%$ for illness. A cross-tabulation between self-reported injury and self-reported illness showed a significant statistical relationship. The association was very weak, with correlation coefficient $=0.12$ (or $12 \%$ ). Of every 100 young-to-middleaged adults who reported having an injury, 41 adults stated that they had an illness in the previous 4 weeks, indicating that less than half a percent of those with an injury had an illness. Concurrently, twice as many young adult females sought medical care than males. On the other hand, males were 2.3 times more likely to record injury, whereas females were 2 times more likely to have had an illness in the previous 4 weeks. Furthermore, the OR of recording better self-assessed health status for males was 1.5 times more than that of females. Outside of the gender differences in self-assessed health status, medical care-seeking behavior, and injuries, the OR of recording good 


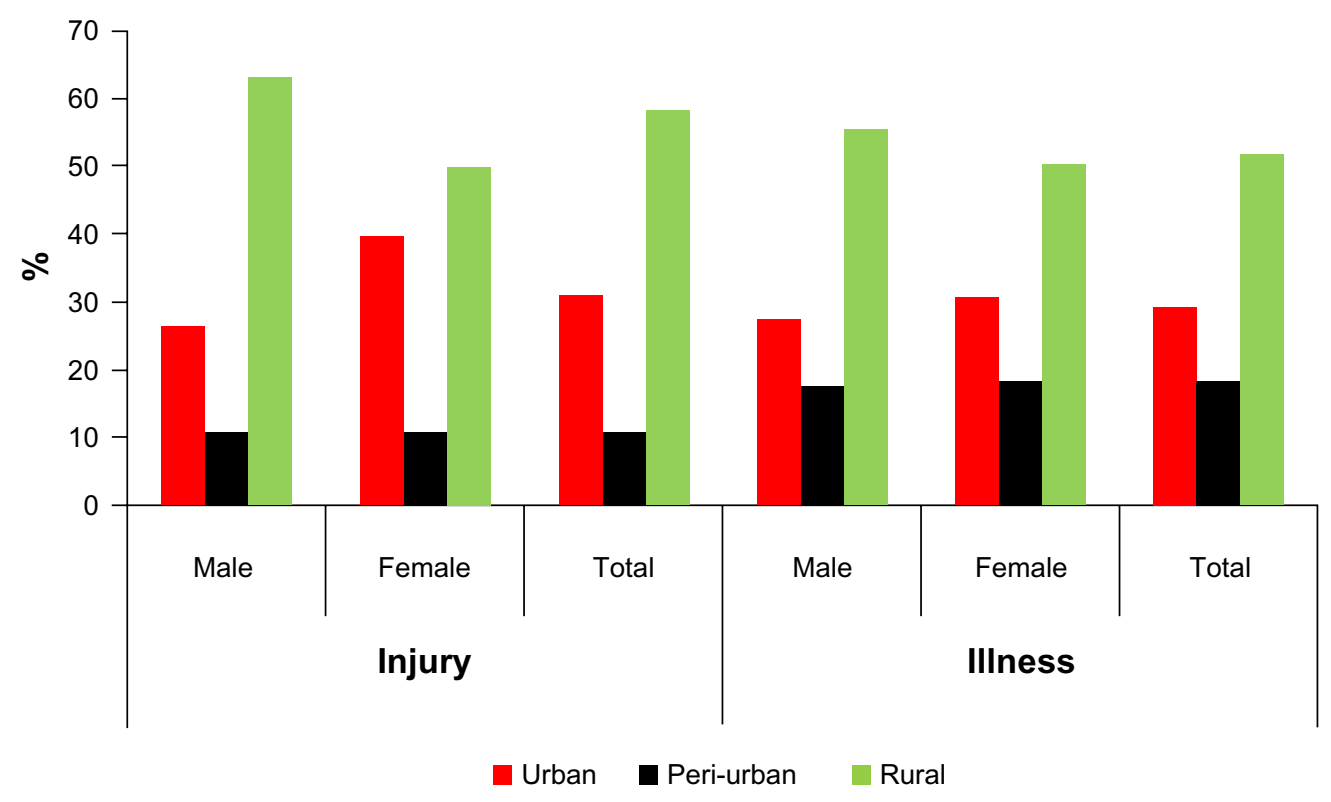

Figure 2 Area of residence of those with injury (\%) and illness (\%) controlled for by gender.

health in married young-to-middle-aged adults was 1.6 times more than their single counterparts, and this was similar for periurban respondents compared to rural young adults. On the other hand, a young adult who sought medical care was $65 \%$ less likely to record good health; young-to-middle-aged adults with tertiary level education were $47 \%$ more likely to record good health; and those who spent more on medical care (ie, medical care-expenditure) were $1 \%$ less likely to have good self-assessed health status.

Empirically, research has established that any investigation of health must combine social, psychological, economic, and biological variables. ${ }^{12-25,32-37}$ Hambleton et al $^{12}$ went further when they disaggregated the contribution of biological and nonmedical conditions of self-assessed health status. They found that $87.7 \%$ of the explanatory power of the good health status of elderly Barbadians could be accounted for by current illness. This study found that current illness accounted for $78.1 \%$, which suggests that illness accounted for less of young adults' health status than for elderly people. One of the challenges in effectively comparing the aforementioned issues (which is embedded in the data) is that the perception of people across different nations is not the same, and this as well as the age component could account for some aspects of the disparity. This study has not only highlighted the role that social determinants play in health status but also demonstrated that they play a greater role in the health

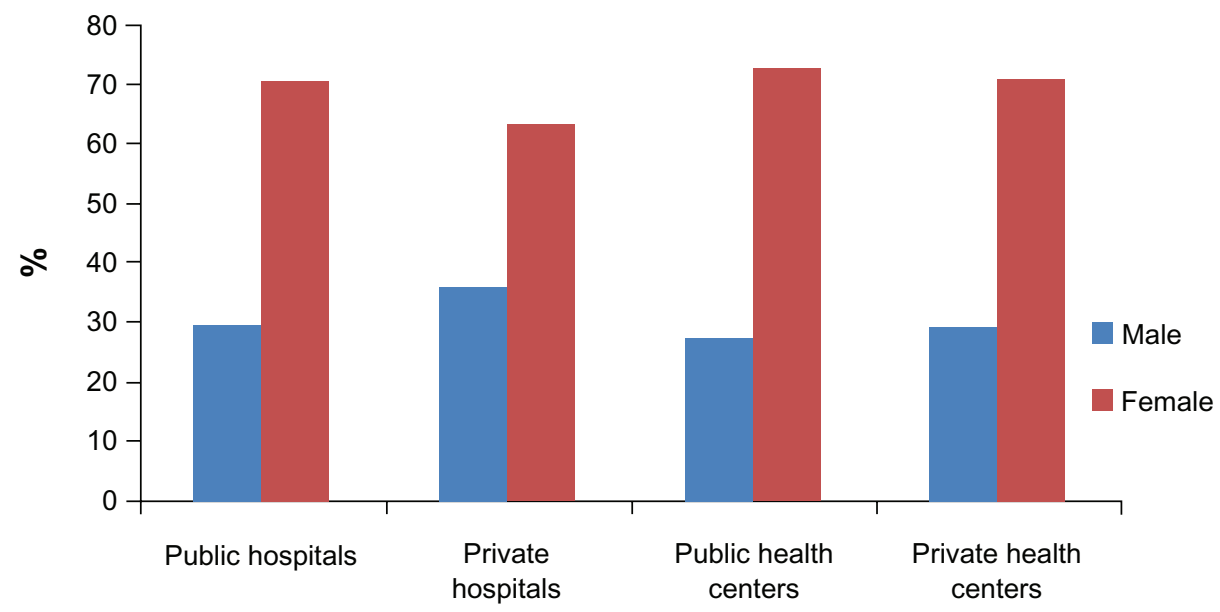

Health care facilities utilization

Figure 3 Gender composition of those who attend health care facilities. 
of younger adults than elderly people. Statistics seemingly show a large percentage of young-to-middle-aged adults being victims of injuries, but the current findings indicate that these represent a small part of the ill-health of young adults. The small percentage of injuries experienced by young-tomiddle-aged adults denotes that using injuries as a guide in health policy intervention would be addressing an even smaller percentage of health status than illnesses. From the aforementioned results, which show that illness contributes more to health status than social determinants, along with injuries, it is clear that despite the cultural and biological differences rooted in both figures, current illness is a strong determinant of self-assessed health status in each region, and if health must combine social, biological, psychological, and ecological determinants, public health interventions that are using any one determinant, in particular injuries, would not be addressing the health concerns of young adults. This empirical evidence concretizes the rationale for social determinants in the discussion and research on health status as well as ill-health.

The findings in this paper showed that social determinants of young-to-middle-aged adults constituted more explanation than for elderly. Therefore, the use of injuries and/or illness to measure and guide public intervention denotes that the health status of 1 in 5 of the young-to-middle-aged adults would have been unaddressed in this effort, and as much as 9 out of 10 cases of injury statistics are used in public policy interventions. Current social determinants of health for elderly Barbadians accounted for $4.1 \%$ of health and historical determinants, suggesting an increased role of biological determinants in the health process with aging. Historical determinants, which included education, occupation, children, economic situations, childhood nutrition, childhood health and diseases, are theoretically a part of social determinants. Disaggregating social determinants to ascertain a value for historical determinants to compare with Hambleton et al's finding in this study found that education was the only factor of those identified in the Barbadian health status, and education accounted for only $0.3 \%$ of the explanatory model in this study. Therefore, within the limitations of this study, meaningful comparison using disaggregated social determinants would be close to impossible as the components are not necessarily the same.

In spite of the limitations in this work, the study can effectively compare self-assessed health status, as our and Hambleton's studies collected this from the population. This study used data for 2007 and Hambleton et al's work using data for December 1999-June 2000, showed that young adults' health was between 1.5 and 1.9 times better than that of elderly Barbadians. Although there are time differences that cannot be discounted in this study, there is emerging information in the reduction of health status with aging. Aging is a natural event. Imagine you purchased a new car, took it home, and locked it away in the car port under cover for 20 years; on removing the covers, although the item was not used, it would have aged. Using the car, however, increases deterioration or depreciation. With regard to human structure, it therefore accounts for illness, health care utilization, and lowered health status. The example of the car symbolizes natural aging and the progressively depleted state of objects, and this is similarly the case for humans. This study revealed that as young people age, the $\mathrm{OR}(\mathrm{OR}=0.97)$ of indicating good health falls, and using the aforementioned statistics would mean that the OR of good health for elderly people should fall. A study by Bourne et $\mathrm{a}^{38}$ showed that illness affecting elderly Jamaicans was more chronic than acute, compared with the converse in this study. With the changes in the typology of illnesses from acute to chronic conditions, the health status of the elderly must be lower than that of young adults. Hence although homicides accounted for more deaths of young-to-middle-aged adults than elderly people, the health status of the former is still greater and this is due largely to the lower risk of biological conditions. Again, the biology of an individual accounts for a greater percentage of self-assessed health than external factors such as injuries from accidents. Injuries resulting from accidents affect 1 in every 100 young adults, making their effect on health less than illness that accounts for 8 in every 100 young adults. Since biological conditions account for more of the selfassessed health of older people, this supports lower health status than in young-to-middle-aged adults and greater health care participation for the former as they seek to address the aging of the organism and increased depreciation owing to old age.

Gompertz's law in Gavrilov and Gavrilova ${ }^{39}$ shows that there is a fundamental quantitative theory of aging and mortality in certain species (eg, humans, human lice, mice, fruit flies, and flour beetles). Gompertz's law went further to establish that human mortality increases 2 -fold with every 8 years of an adult's life, which means that aging increases in geometric progression. This phenomenon means that human mortality increases with age in the human adult, but this becomes less progressive in advanced aging. Thus, biological aging is a process by which the human cells degenerate with aging (ie, the cells die with increasing speed in older people), which is explored in evolutionary biology. ${ }^{40-43}$ But studies 
have shown that using an evolutionary theory for "late-life mortality plateaus" fails because of the arguable unrealistic set of assumptions that the theory uses to establish itself. ${ }^{4-46}$

Aging, therefore, denotes a gradual deterioration in living organisms, as well as other nonliving items, which account for the greater demand for medical care. Medical care-seeking behavior could indicate either preventative or curative care. This study revealed that the OR of good health of young-to-middle-aged adults in Jamaica declines by $65 \%$ for those who seek medical care. Medical care for young-to-middle-aged adults, therefore, is a good measure of curative rather than preventative care. This work revealed that 94 out of every 100 young-to-middle-aged adults who sought medical care were ill. This reinforces the cultural perception of illness and the reason why young-to-middleaged adults seek health-care is curative rather than preventative for this group.

In this study, illness is substantially a female phenomenon. Young adult females were twice as likely to report an illness, and this justifies their greater probability of using medical care in order to address ill-health. These findings have a high degree of validity as statistics from the Jamaica Ministry of Health showed that females attended health care institutions twice as often as men for curative care since 2000-2007. ${ }^{9}$ Since 1988, statistics obtained from Jamaicans in national cross-sectional surveys revealed that females were about twice as likely to report an illness and use medical care than males. This reinforced the cultural bias of illness and health care facilities. Health care facilities are primarily governed by females for females, and this adds to the cultural handicap of males attending public health care institutions on experiencing ill-health. The feminization of health care facilities and the large percentage of people, in particular females, who use public health care institutions is another rationale for males using private health care facilities. On the other hand, males will attend medical care facilities when ill-health interfaces with their economic livelihood and its severity is such that this is the only avenue. This is not atypical to Jamaica, as a qualitative study in Pakistan on street children found that boys would attend formal health care if it affected their economic livelihood and health conditions were severe. ${ }^{47}$ Another study conducted in Anyigba, in North-Central Nigeria, found that 85 out of every 100 respondents waited for less than a week after the onset of illness to seek medical attention, and that 57 out of every 100 indicated that they would recover without treatment. ${ }^{48}$

A Caribbean anthropologist ${ }^{49}$ stated that the macho socialization of the Caribbean male accounts for his unwill- ingness to seek medical care. Caribbean males, including Jamaicans, are socialized to be strong, not to show weakness, and to be involved in particular tasks to exhibit their masculinity. As a result, illness is seen as signaling weakness, therefore, accounting for the reasons why they are skeptical about visiting medical institutions and often wait for the condition to become severe. On visiting medical practitioners, it is sometimes very difficult for traditional medical practitioners to offer a cure. This then offers an explanation for females living longer than males. Although the current findings showed that the odds of recording good health are 1.5 times greater for young adult males, a part of this is owing to the reality that often males do not see themselves as ill, they visit medical practitioners less, and this justifies the higher mortality among them than among females. The social determinants are, therefore, offering explanations for the biological issues as well. Challenges to the implementing of health interventions to improve the health of young-to-middle-aged adults, in particular males, are numerous, as the definition of illness and severity of symptoms reduce the quality of life of people, and this finding concurs with a previous study by Williams et al. ${ }^{50}$ Unlike this study, Williams et $\mathrm{a}^{50}$ found that medical care-seeking behavior did not differ significantly between the sexes. Like the current study, Dunlop et $\mathrm{al}^{51}$ found that African American men had fewer physician contacts than minority and non-Hispanic white women. The irresponsiveness of young adult males in seeking health care comparable to their female counterparts in Jamaica extends to even older African American men.

With the advancement in literacy and numeracy in the world since the 19th century, specifically in Jamaicans since 1960 (ie, educational levels), empirical findings showed that education is among the social determinants that influence health status. ${ }^{12-26}$ Education affects health directly and indirectly. A study on twins in the United States found that more years of schooling (ie, education) were associated with healthier patterns of behavior, ${ }^{52}$ which is an example of the direct impact of education on health. In the Fujiwara and Kawachi ${ }^{52}$ work, increased schooling was associated with a reduction in smoking habits and other such healthier practices. This study concurs with the literature, as the OR of good health status of young-to-middle-aged adults with tertiary level education is 1.5 times more than that of those with primary or below education. The indirect way in which education affects health can be measured using social hierarchy. The present findings revealed that the middle class who are educated were 1.5 times more likely to report good health status and that wealth 
or income was not correlated with good health status, nor did the self-assessed health status of wealthy social hierarchies did differ from that of the poor social hierarchies.

Empirical evidence exists that the social determinants of health include marital status. Some research showed that married people are healthier than unmarried people. ${ }^{12-25,53-58}$ The findings of Koo, et $\mathrm{al}^{54}$ revealed that being married was a "good" motive for an increase in psychological and subjective wellbeing in old age. Smith and Waitzman ${ }^{55}$ offered the explanation that wives were found to dissuade their husbands from particularly risky behaviors, such as the use of alcohol and drugs, and would ensure that they maintained a strict medical regimen coupled with proper eating habits. ${ }^{53,56}$ In an effort to contextualize the psychosocial and biomedical health status of a particular marital status, one demography cited that the death of a spouse meant closure to daily communication and shared activities, which sometimes translates into depression that affects wellbeing, more so for the elderly who would have had a greater investment in a partner. ${ }^{57}$ They pointed to a paradox within this discourse as "... this is not observed among men". To provide a holistic base to the argument, a sentence from of Delbés and Gaymu ${ }^{57}$ can be quoted "The widowed have a less positive attitude towards life than married people, which is not an unexpected result". ${ }^{57}$ This study concurs with the literature that the health status of married young-to-middle-aged adults is greater than those who are single, but that this was only expressed by females. These findings highlight the value of marriage to females that commences at an early age and seemingly that the benefits of marriage are not for males. This is clearly not the case, as a study by Bourne, ${ }^{58}$ using data on Jamaicans, found that the OR of reported good health was 1.6 times more for married males than their female counterparts.

\section{Conclusion and policy recommendations}

In summary, statistics for 2007 revealed that 1 of every 2 Jamaicans was 15-44 years old. This indicates the importance of research being conducted on this age group. With the demographic reality of young-to-middle-aged adults in the country, using injury to examine health is narrow and grossly inadequate, and fails to understand the matter of health. Health is more than illness, as it incorporates social, economic, psychological, ecological, and biological determinants. Although the biological determinant of the self-assessed health of young adults is predominant in health determinants, injury accounts for a miniscule percentage of illness, and so using injury to formulate intervention policies would be lacking in depth to effectively address the health of this cohort. Although the health of young adult Jamaicans is very good, there are many health disparities between the sexes, which support inequities in health outcomes between males and females.

This study highlights some of the health disparities between the sexes and affords research findings that can be used to refashion health policies and research focus in the future. Health policies must use the wide spectrum of health determinants in order to address the multidimensional nature of health. The use of injuries to measure and guide policies and programs, because seemingly there are many young-to-middle-aged adults who are affected, is inappropriate and does not capture the gamut of illness or even health of this group of people.

The health disparities identified are among the reasons for health inequities in health outcomes, and this should justify a call for a research and policy direction that includes technical, financial, and moral, as these would provide additional explanations for health disparities, choices, inequities, and/or inequalities in health outcomes among young adults.

Another issue that must be addressed by public health practitioners is typology of injuries experienced by youngto-middle-aged adults in Jamaica. Although only a small percentage of the study population indicated having had an injury during a 4-week period, the findings emerged that the majority of those who had injuries from motor vehicles were more from domestic accidents and domestic incidents than outside violence. These findings suggest that violence has less impact on young adults than older adults, and so public health specialists should place more emphasis on addressing domestic accidents than violence.

\section{Acknowledgment}

The authors thank the Data Bank in Sir Arthur Lewis Institute of Social and Economic Studies, the University of the West Indies, Mona, Jamaica for making the data set (Jamaica Survey of Living Conditions, 2007) available for use in this study.

\section{Disclosure}

The authors report no conflict of interest with this work.

\section{References}

1. Frederick J, Hamilton P, Jackson J, et al. Issues affecting reproductive health in the Caribbean. In: Morgan O, editor. Health Issues in the Caribbean. Kingston: Ian Randle; 2005:41-50.

2. McNeil P. Coping with teenage pregnancy. In: Morgan O, editor. Health Issues in the Caribbean. Kingston: Ian Randle; 2005:51-57.

3. Bain B. HIV/AIDS - the rude awakening/stemming the tide. In: Morgan O, editor. Health Issues in the Caribbean. Kingston: Ian Randle; 2005: $62-76$. 
4. Douglas K-G. Patterns of substance use among adolescents students in Jamaica. In: Morgan O, editor. Health Issues in the Caribbean. Kingston: Ian Randle; 2005:77-78.

5. Abel W. Substance use - health consequences. In: Morgan O, editor. Health Issues in the Caribbean. Kingston: Ian Randle; 2005:79-86.

6. McDonald A. Injuries - the broad picture. In: Morgan O, editor. Health Issues in the Caribbean. Kingston: Ian Randle; 2005:87-92.

7. McCartney TB. The health impact of injuries (Abridged). In: Morgan O, editor. Health Issues in the Caribbean. Kingston: Ian Randle; 2005:93-95.

8. Statistical Institute of Jamaica, (STATIN). Demographic Statistics, 1970-2008. Kingston: STATIN; 1971-2009.

9. Jamaica, Ministry of Health (MoH). Annual report, 1990-2007. Kingston: MoH; 1991-2009.

10. Pan American Health Organization (PAHO). Health in the Americas 2007, Volume II - Countries. Washington DC: PAHO; 2007.

11. World Health Organization (WHO). Health Statistics, 2009. Geneva: WHO; 2009:50.

12. Hambleton IR, Clarke K, Broome HL, et al. Historical and current predictors of self-reported health status among elderly persons in Barbados. Revista Panamericana de Salud Pública. 2005;17: 342-352.

13. Graham H. Social determinants and their unequal distribution clarifying policy understanding. The Milbank Quarterly. 2004;82:101-124.

14. Pettigrew M, Whitehead M, McIntyre SJ, et al. Evidence for public health policy on inequalities: 1: the reality according to policymakers. J Epidemiol Community Health. 2004;5:811-816.

15. Asnani MR, Reid ME, Ali SB, et al. Quality of life in patients with sickle cell disease in Jamaica: rural-urban differences. Rural Remote Health. 2008;8:890-899.

16. Bourne PA, McGrowder DA. Rural health in Jamaica: examining and refining the predictive factors of good health status of rural residents. Rural Remote Health. 2009;9:1116.

17. Bourne PA. Medical sociology: modelling well-being for elderly people in Jamaica. West Indian Med J. 2008;57:596-604.

18. Bourne PA. Health determinants: using secondary data to model predictors of wellbeing of Jamaicans. West Indian Med J. 2008;57:476-481.

19. Grossman M. The Demand for Health - a Theoretical and Empirical Investigation. New York: National Bureau of Economic Research; 1972.

20. Smith JP, Kington R. Demographic and economic correlates of health in old age. Demography. 1997;34:159-170.

21. Wilkinson RG, Marmot M. Social Determinants of Health. The Solid Facts, 2nd ed. Copenhagen: World Health Organization; 2003.

22. Solar O, Irwin A. A conceptual framework for analysis and action on the social determinants of health. Discussion paper for the Commission on Social Determinants of Health DRAFT April 2007. Available from: http://www.who.int/social_determinants/resources/csdh_framework_ action_05_07.pdf. Accessed Apr 29, 2009.

23. Bourne PA, Rhule J. Good health status of rural women in the reproductive ages. Int J Collaborative Res on Int Med and Public Health. 2009; $1: 132-155$.

24. Bourne PA. A theoretical framework of good health status of Jamaicans: using econometric analysis to model good health status over the life course. North Am J of Med Sci. 2009;1:86-95.

25. Bourne PA. Socio-demographic determinants of health care-seeking behaviour, self-reported illness and self-evaluated health status in Jamaica. Int $J$ Collaborative Res on Int Med and Public Health. 2009;1:101-130

26. Bourne PA. Demographic shifts in health conditions of adolescents 10-19 years, Jamaica: using cross-sectional data for 2002 and 2007 North Am J of Med Sci. 2009;1:125-133.

27. Planning Institute of Jamaica (PIOJ), Statistical Institute of Jamaica (STATIN). Jamaica Survey of Living Conditions, 1989-2007. Kingston: PIOJ, STATIN;1989-2008.
28. World Bank, Development Research Group, Poverty and Human Resources. Jamaica Survey of Living Conditions, 1988-2000. Basic information. Washington: The World Bank; 2002. http:// siteresources.worldbank.org/INTLSMS/Resources/3358 986-1181743055198/3877319-1190214215722/binfo2000.pdf. Accessed Sep 2, 2009

29. Statistical Institute of Jamaica. Jamaica Survey of Living Conditions, 2007 [Computer file]. Kingston, Jamaica: Statistical Institute of Jamaica [producer], 2007. Kingston, Jamaica: Planning Institute of Jamaica and Derek Gordon Databank, University of the West Indies [distributors]; 2008.

30. Homer D, Lemeshow S. Applied Logistic Regression. 2nd ed. New York: John Wiley \& Sons Inc; 2000.

31. Cohen L, Holliday M. Statistics for Social Sciences. London: Harper \& Row; 1982.

32. Casas JA, Dachs JN, Bambas A. Health disparity in Latin America and the Caribbean: the role of social and economic determinants. In: Pan American Health Organisation. Equity and health: Views from the Pan American Sanitary Bureau. Washington DC. Occasional Publication; 2001:No.8;22-49.

33. Engel G. A unified concept of health and disease. Perspect Biol Med. 1960;3:459-485

34. En gel G. The care of the patient: art or science? Johns Hopkins Med J. 1977;140:222-232.

35. Engel G. The need for a new medical model: a challenge for biomedicine. Science. 1977;196:129-136.

36. Engel G. The biopsychosocial model and the education of health professionals. Ann N Y Acad Sci. 1978;310:169-181.

37. Engel GL. The clinical application of the biopsychosocial model. Am J of Psychiatry. 1980;137:535-544.

38. Bourne PA, McGrowder DA, Crawford TV. Decomposing mortality rates and examining health status of the elderly in Jamaica. Open Geriatr Med J. 2009;2:34-44.

39. Gavrilov LA, Gavrilova NS. The reliability theory of aging and longevity. J Theor Biol. 2001;213:527-545.

40. Medawar PB. Old Age and Natural Death Mod Q. 1946;2:30-49. Reprinted in the Uniqueness of the Individual (Medawar P B ed. 1958: 17-43). New York: Basic Books.

41. Carnes B, Olshansky SJ. Evolutionary perspectives on human senescence. Popul Dev Rev. 1993;19:793-806.

42. Carnes BA, Olshansky SJ, Gavrilov LA, Gavrilova NS, Grahn D. Human longevity: nature vs nurture - fact or fiction. Persp Biol Med. 1999;42:422-441.

43. Charlesworth B. Evolution in Age-structured Populations, 2nd ed. Cambridge: Cambridge University Press; 1994.

44. Mueller L, Rose MR. Evolutionary theory predicts late-life mortality plateaus. Proc Natl Acad Sci U S A. 1996;93:249-253.

45. Charlesworth B, Partridge L. Ageing: leveling of the grim reaper. Curr Biol. 1997; 7:R440-R442.

46. Pletcher SD, Curtsinger JW. Mortality plateaus and the evolution of senescence: why are old-age mortality rates so low? Evolution. 1998;52:454-464.

47. Wachter, KW. Evolutionary demographic models for mortality plateaus. Proc Natl Acad Sci U S A. 1999;96:10544-10547.

48. Ali M, de Muynck A. Illness incidence and health seeking behaviour among street children in Rawalpindi and Islamabad, Pakistan - a qualitative study. Child Care Health Dev. 2005;31: 525-532.

49. Chevannes B. Learning to be a Man: Culture, Socialization and Gender Identity in Five Caribbean Communities. Kingston, Jamaica: University of the West Indies Press; 2001.

50. Williams RE, Black CL, Kim H-Y, et al. Determinants of health-careseeking behaviour among subjects with irritable bowel syndrome. Aliment Pharmacol Ther. 2006;23:1667-1675.

51. Dunlop DD, Manheim LM, Song J, Chang RW. Gender and ethnic/racial disparities in health care utilization among older adults. J Gerontol B Psychol Sci Soc Sci. 2002;57B:S221-S233. 
52. Fujiwara T, Kawachi I. Is education causally related to better health? A twin fixed-effect study in the USA. Int J Epidemiol. 2009;1-13.

53. Gore WR. Sex, marital status, and mortality. Am J Sociol. 1973;30: 189-208.

54. Koo J, Rie J, Park K. Age and gender differences in affect and subjective wellbeing. Geriatr Gerontol Int. 2004;4:S268-S270.

55. Smith KR, Waitzman NJ. Double jeopardy: interaction effects of marital and poverty status on risk of mortality. Demography. 1994;31:487-507.
56. Ross CE, Mirowsky J, Goldsteen K. The impact of the family on health. J Marriage Fam. 1990;52:1059-1078.

57. Delbés C, Gaymu J. The shock of widowed on the eve of old age: male and female experience. Demography. 2002;3:885-914.

58. Bourne PA. Self-evaluation of health of married people in Jamaica. Health. 2009;1:63-92.

\section{Publish your work in this journal}

Patient Related Outcome Measures is an international, peer-reviewed, open access journal focusing on treatment outcomes specifically relevant to patients. All aspects of patient care are addressed within the journal and practitioners from all disciplines are invited to submit their work as well as healthcare researchers and patient support groups. Areas covered will include: Quality of life scores; Patient satisfaction audits; Treatment outcomes that focus on the patient; Research into improving patient outcomes; Hypotheses of interventions to improve outcomes; Short communications that illustrate improved outcomes; Case reports or series that show an improved patient experience; Patient journey descriptions or research.

\footnotetext{
Submit your manuscript here: http://www.dovepress.com/patient-related-outcome-measures-journal
} 